\title{
American Library Association (ALA) no Second Life (SL) ${ }^{1}$
}

\section{Richele Grenge Vignoli}

\author{
Especialista em Gestão de Bibliotecas \\ Universitárias pela Universidade Estadual de \\ Londrina (UEL) em 2010..Professora auxiliar do \\ Departamento de Ciência da Informação da UEL
}

Maria Inês Tomael

\begin{abstract}
Doutora em Ciência da Informação pela Escola de Ciência da Informação da Universidade Federal de Minas Gerais (ECI/UFMG).Professora adjunto do Departamento de Ciência da Informação da UEL. Coordenadora do Programa de Pós-graduação em Ciência da Informação (mestrado acadêmico)
\end{abstract}

A American Library Association (ALA) está inserida no contexto de Realidade Virtual (RV) em $3 D$, por meio de sua atuação no Second Life (SL), com a ALA Island. Esta pesquisa teve como objetivo analisar o atendimento virtual a bibliotecários no SL; identificar produtos e serviços que a ALA oferece no SL e analisar sua infraestrutura. Para a coleta de dados, foi utilizada a análise documental, ação em que a ALA Island foi observada/explorada e estruturada em dados; e o questionário - enviado a uma bibliotecária da ALA Island. Os resultados demonstram que a atuação da ALA no SL tem como propósito central a divulgação de seus projetos, os eventos físicos e os virtuais e o apoio ao bibliotecário em sua vida profissional. A ALA está inserida em diversos recursos da Web 2.0, além do SL, como blogs, wikis, sites de relacionamento, entre outros. Toda a trajetória da ALA foi analisada, assim como as especificidades do seu trabalho realizado para os bibliotecários. Observou-se que o atendimento a bibliotecários no SL é realizado por meio de robôs e indicação de notecards e hiperlinks informativos. No SL, a ALA disponibiliza diversos serviços e produtos aos bibliotecários, como os relacionados com os escritórios, comitês e instituições, além dos serviços e produtos disponíveis no site e no escritório da ALA em Washington-DC e de seus representantes. Os recursos da ALA e do SL, assim como a inserção de bibliotecários em Realidade Virtual (RV) precisam ser estudados por meio

\footnotetext{
${ }^{1}$ Resultados parciais de projeto de pesquisa financiado pelo CNPq.
} 
de pesquisas, para dinamizar e aproximar essa realidade desses profissionais.

Palavras-chave: American Library Association (ALA); Second Life (SL); ALA Island; Realidade Virtual (RV).

\section{American Library Association (ALA) in Second Life (SL)}

The American Library Association ( $A L A)$ is inserted in the $3 D$ virtual reality environment with the ALA Island in Second Life (SL). The purpose of this study was to analyze the virtual support to librarians in $S L$, to identify ALA products and services offered in $S L$ and to examine its infrastructure. The document analysis method was used to obtain useful data about ALA Island as well as a questionnaire which was sent to an ALA librarian. The results show that the main purpose of ALA performance in $S L$ is dissemination of projects, physical and virtual events, and support for libraries in their professional lives. In addition to $S L$, there are, embedded in $A L A$, Web 2.0 apps such as blogs, wikis, social networks, among others. ALA's trajectory was examined as well as librarian support. The librarian support in $S L$ is performed by robots and interactive tools, such as notecards and informative hyperlinks. In $S L$, the $A L A$ Island makes services and products available to help librarians, related with offices, committees and institutions. In addition, it offers services and products in its site, and office in Washington D.C and its representatives. More studies are needed on the resources of the ALA and $S L$ and the integration of librarians in Virtual Reality (VR) to help and bring this opportunity to these professionals.

Keywords: American Library Association (ALA); Second Life (SL); ALA Island; Virtual Reality.

Recebido em 05.05.2012 Aceito em 23.04.2012

\section{Introdução}

Profissionais das mais diversas áreas do conhecimento estão descobrindo no Second Life (SL) diversas oportunidades de exercer e inovar em suas profissões. O SL apresenta aos usuários e profissionais um ambiente virtual em 3D repleto de lugares a serem explorados e com 
milhares de usuários em potencial, para a propagação de diversas atividades.

O SL tornou-se um ambiente muito visado para pessoas e empresas empreendedoras, pois, segundo Ferraz (2007), sua economia chega a movimentar cerca de 1,6 milhões de dólares a cada 24 horas. O autor indica, também, que existem no SL cerca de 30 mil usuários logados a cada uma hora. Tais estatísticas comprovam principalmente o potencial econômico do SL, fato evidenciado pela presença de muitas empresas e marcas nesse ambiente.

Além das empresas que buscam a comercialização de seus produtos e serviços, no SL existe a presença de muitas universidades e instituições de ensino. García (2007) esclarece que só em 2007, o SL já registrava mais de 150 universidades e instituições de ensino nacionais e internacionais presentes nesse ambiente. Essas instituições adotaram o SL pelas facilidades encontradas para o Ensino à Distância (EAD), em um ambiente propício para o ensino e aprendizagem virtual, que trazem avanços e inovações para área da educação.

A American Library Asociation (ALA), considerada como a entidade com maior respresentatividade mundial na área da Ciência da Informação e da Biblioteconomia, aproveitou o nicho educacional e tecnológico do SL para promover e divulgar as atividades dos bibliotecários pelo mundo. Neste estudo, investigou-se a participação da ALA no SL (ALA Island), assim como todas as atividades da instituição apresentadas nesse espaço virtual.

Para isso, os objetivos desse estudo foram: analisar o atendimento virtual a bibliotecários no SL; identificar produtos e serviços que a ALA oferece no SL; e analisar a infraestrutura da ALA no SL.

Para a consecução dos objetivos, foram adotados dois procedimentos metodológicos:

10. - pesquisa documental: análise dos ambientes virtuais do SL e da ALA Island, assim como do site da ALA e dos recursos da Web 2.0 em que a ALA participa; e

20. - questionário: enviado por e-mail à bibliotecária da ALA responsável pela ALA Marketing Merbership, para identificar os propósitos da inserção da ALA no SL, bem como as estruturas físicas, materiais e de pessoal.

A bibliotecária respondente e seu avatar estão presentes em muitos locais da ALA Island, principalmente em notecards ${ }^{2}$ e em diversos hiperlinks.

O resultado desta pesquisa pode subsidiar os bibliotecários e profissionais da informação que buscam inovar em seu trabalho. Para Kirner, Toti e Costa (2006), novos ambientes virtuais em bibliotecas precisam ser criados, como, por exemplo, os ambientes de Realidade Virtual (RV) existentes nas bibliotecas do SL.

\section{Second Life}

2 São itens informativos sobre algum tema, podem ser apresentados por meio de textos, som, hiperlinks, entre outros.

Perspectivas em Ciência da Informação, v.17, n.2, p.92-108, abr./jun. 2012 
O Second $\mathrm{Life}^{3}$ (SL) - "Segunda Vida" - foi criado e desenvolvido por Philip Rosedale, em 2003. O SL é um ambiente de Realidade Virtual com jogabilidade online em 3D, que possibilita a participação do usuário ou residente ${ }^{4}$ por meio da realização de um cadastro prévio, pelo download do programa e pela criação de um personagem virtual (avatar) que o represente nesse ambiente.

O SL apresenta uma dualidade de conceituação tanto na literatura, quanto nas mídias, já que é caracterizado, muitas vezes, como recurso Web 2.0 e, em outras, como game ou jogo virtual. Alguns autores relatam essa dualidade de caracterização, como Accioly (2007), o qual argumenta que o SL já nasceu na ambiguidade, pois a mídia o enquadra como game e, também, como Rede Social.

García (2007) esclarece que o SL não se enquadra nos padrões de games ou jogos virtuais, mesmo que apresente características de um Massive (ly) Multiplayer Online Role-Playing Games (MMORPG), jogos online que possibilitam qualquer número de jogadores simultâneos com base no modelo de cliente-servidor.

Embora as características de um MMORPG sejam aparentemente aplicáveis ao SL, García (2007) demonstra algumas diferenças que descaracterizam o SL como game ou jogo virtual, são elas: a elasticidade do personagem em se modificar quando quiser; a falta de uma temática específica e primordial a qualquer tipo de game; a insuficiência de objetivos traçados e de premiações como de pontos, armas, acessórios ou "vidas". Porém, o diferencial mais expressivo do SL é a sua relação de infinitude, pois o ambiente não apresenta, ao usuário, nenhum fim ou final determinado (GARCÍA, 2007), o que definitivamente não condiz com jogos virtuais.

Sobre o SL possuir um fim ou final, Accioly (2007, p.13) faz uma analogia entre a relação da vida no $S L$ e a vida real, quando diz que "A vida é um jogo, certamente. A diferença é que, nele, nós ainda morremos no final." A autora compara a vida a um jogo, já que ambos possuem um final. No entanto, no SL a vida virtual não possui um fim, a não ser que o residente exclua o seu personagem.

Outra característica predominante ao SL refere-se à criação dos personagens denominados "avatar". Moura e Carvalho (2007) se baseiam na crença hinduísta para definir um avatar e os classificam como seres divinos que assumem formas humanas ou de animais. Um avatar pode ser criado sob qualquer aparência, que partirá da imaginação do usuário, o qual pode também criá-lo sob sua própria semelhante física.

De acordo com o pressuposto de que o SL não pode ser caracterizado como game ou jogo virtual, alguns autores utilizam os preceitos da Web 2.0 para conceituá-lo.

A Web 2.0, termo desenvolvido por Tim O'Reily em 2004, durante uma conferência entre as empresas O'Reily e Media Live Internacional

\footnotetext{
${ }^{3}$ Disponível em: <www.secondlife.com>. Acesso em: 14 fev. 2011.

${ }^{4}$ Denominação utilizada para os usuários no SL.
} 
(O'REILY, 2006), inaugurou o movimento de colaboração, interação e compartilhamento da informação e de conteúdos na web. Diante disso, a Web 2.0 torna possível que qualquer usuário possa desenvolver, modificar e, principalmente, compartilhar conteúdos na web. A web passa a ser vista como espaços colaborativos em que todos podem participar.

A aplicação do SL como recurso Web 2.0 pode ser entendida sobre o prisma da colaboração, da criação, da construção, do compartilhamento e, principalmente, pelas relações estabelecidas no ambiente, 0 que 0 caracteriza como Rede Social. O SL promove a interação e o compartilhamento ao extremo, já que a $\operatorname{Linden} \operatorname{Lab}^{5}$ (LL) mantém o código fonte do SL aberto desde 2007, o que torna possível que qualquer usuário possa modificar ou criar conteúdos no ambiente.

Sendo assim, o SL segue os preceitos da Web 2.0, que são de colaboração, interação, compartilhamento e, principalmente, de liberdade de criação pelos usuários. Para Zagalo e Pereira (2008), o SL é a imagem da $W e b 2,0$, já que é um ambiente que vive aberto para as construções e criações dos usuários.

O fato é que a abertura do código fonte do SL possibilitou aos usuários mais que formas de criação ou interação, pois fez com que muitos residentes começassem a participar da economia do $S L$ e, principalmente, a ganhar dinheiro. Com um espaço próprio para a criação de objetos e produtos (SandBox e Skybox), os usuários do SL desenvolveram a comercialização de uma infinidade de artefatos aos avatares, como, por exemplo, roupas, sapatos, órgãos humanos utilizados para acentuar detalhes nos avatares, entre outros.

A partir disso, o SL disponibiliza aos residentes a opção de viver de fato uma segunda vida, já que, em algum momento, também é possível ganhar dinheiro com criações e comércio de produtos no SL. Essa segunda vida, ainda que projetada em realidade virtual 3D, não deixa de ser real, já que todos os comandos e ações praticadas no SL são realizados por pessoas reais, ou seja, humanos.

Toda a economia no SL gira em torno de sua moeda única, o Linden Dólar, que é cotada em dólar. García (2007) explica que a principal característica do Linden Dólar é que a moeda virtual não possui apenas um valor simbólico, é possível o intercâmbio em dólares e em outras moedas. Terrenos, casas, carros ou qualquer objeto no SL são comercializados em linden dólars.

Outro ponto em constante evolução no SL são as ilhas de EAD, representadas por diversas instituições no mundo todo, como, por exemplo, a Universidade de Harvard, nos EUA, ou da Pontifícia Universidade Católica do Rio de Janeiro (PUC - RIO), no Brasil.

O SL demonstra sua aceitação por meio do número crescente de residentes cadastrados em todo o mundo. Só em janeiro de 2010, a interface do SL registrava que, nos últimos dois meses, 1.383 .628 residentes se conectaram ao SL. Soares (2009) afirma que existem cerca de 300 mil usuários brasileiros cadastrados no SL. O impacto do SL tem

\footnotetext{
${ }^{5}$ Empresa que administra o SL.
} 
atingido diversas organizações da Ciência da Informação, entre elas a ALA.

\section{American Library Association (ALA) ${ }^{6}$}

As primeiras iniciativas para a formação de uma comissão permanente para a área da Biblioteconomia ocorreram em 1853, em uma conferência que reuniu aproximadamente oitenta bibliotecários nos Estados Unidos. Mas, a ALA só foi fundada anos mais tarde, quando mais de 100 bibliotecários se reuniram exatamente no dia seis de outubro de 1876, para, então, concretizarem a ALA, como a principal representante dos bibliotecários e da Biblioteconomia pelo mundo.

A fundação da ALA foi protagonizada pela presença de personagens ilustres para a Biblioteconomia, como Melvil Dewey, Justin Winsor, C.A. Cutter, entre outros.

Depois de mais de cem anos, o conselho da ALA restabeleceu o seu lema: "Leitura de Qualidade, para o maior número de pessoas, pelo menor custo". A ALA nasceu e permanece com objetivos concretos em desenvolver diretrizes que venham aperfeiçoar a atuação dos bibliotecários, das bibliotecas e de unidades de informação pelo mundo.

Em 2000, criou a "ALA Meta 2000", que teve como preceito a liberdade intelectual dentro e fora das bibliotecas, preceito que perdura até hoje. Em 2005, a ALA divulga novas metas, denominadas de "ALAction 2005", as quais partiram da ideia de que a informação deve estar disponível para todos e que a ALA deverá ser líder no uso da tecnologia, além de gerar o aprendizado compartilhado entre seus membros.

Ainda no ano de 2005, durante a Conferência Anual, foi desenvolvido o projeto "ALA frente a 2010". Nesse projeto, a missão e a visão da ALA sofreram algumas alterações e a missão declarada é: "Ser líder e conduzir o desenvolvimento, a promoção e a melhoria dos serviços de biblioteca e de informação, tal como da profissão do bibliotecário para a aprendizagem constante e a garantia do acesso à informação para todos" (ALA, 2010) e a visão da ALA: "O valor das bibliotecas e bibliotecários está em conectar pessoas ao conhecimento registrado em todas as formas. O público tem direito a uma sociedade da informação aberta e livre" (ALA, 2010).

Em 2006, as prioridades da ALA em relação às áreas de atuação foram expandidas para as "Sete Áreas-Chave de Atuação": 1) diversidade; 2) acesso equitativo à informação e serviços de biblioteca; 3) educação e aprendizagem ao longo da vida; 4) liberdade intelectual; 5) advocacy para Bibliotecas e para os profissionais; 6) competência; e 7) excelência Organizacional.

Em 2007, a ALA fez sua estreia no Second Life e demonstrou inovação ao atuar em Ambientes Virtuais e de Realidade Virtual em 3D. Em 2009, a ALA redefine suas metas novamente e cria o "ALAHead 2015"

\footnotetext{
${ }^{6}$ Disponível em: <www.ala.org>. Acesso em: 14 fev. 2011.
} 
- "Ala Frente a 2015", que contou com a participação de 9.000 membros no desenvolvimento do projeto, que só foi aprovado em junho de 2010.

De acordo com a trajetória e projetos da ALA ao longo do tempo, observa-se que tanto a missão quanto a visão e as metas condizem com as ações da ALA pela busca da melhoria na qualidade da atuação dos bibliotecários, no atendimento das bibliotecas e no desenvolvimento intelectual e informacional das pessoas de modo em geral.

A ALA, sediada na cidade de Chicago, nos Estados Unidos da América, possui em média 65.000 membros espalhados pelo mundo. Estima-se que somente $3,5 \%$ desses não sejam de nacionalidade americana (ALA, 2010), uma porcentagem baixa, já que a ALA possui instituições associadas pelo mundo todo. No Brasil, a única instituição associada à ALA é a Federação Brasileira de Associações de Bibliotecários, Cientistas da Informação e Instituições (FEBAB) ${ }^{7}$.

Por meio do site da ALA, o bibliotecário pode obter informações sobre bibliotecas de várias nacionalidades, participar como membro da ALA e se associar ou, ainda, associar a biblioteca ou unidade de informação em que atua. Como usuário comum ou como não-membro, o bibliotecário pode participar, opinar e se atualizar em diversos canais de comunicação e de debate disponíveis pela ALA na web.

\section{A ALA Island}

Figura 1 - Visão panorâmica da ALA Island

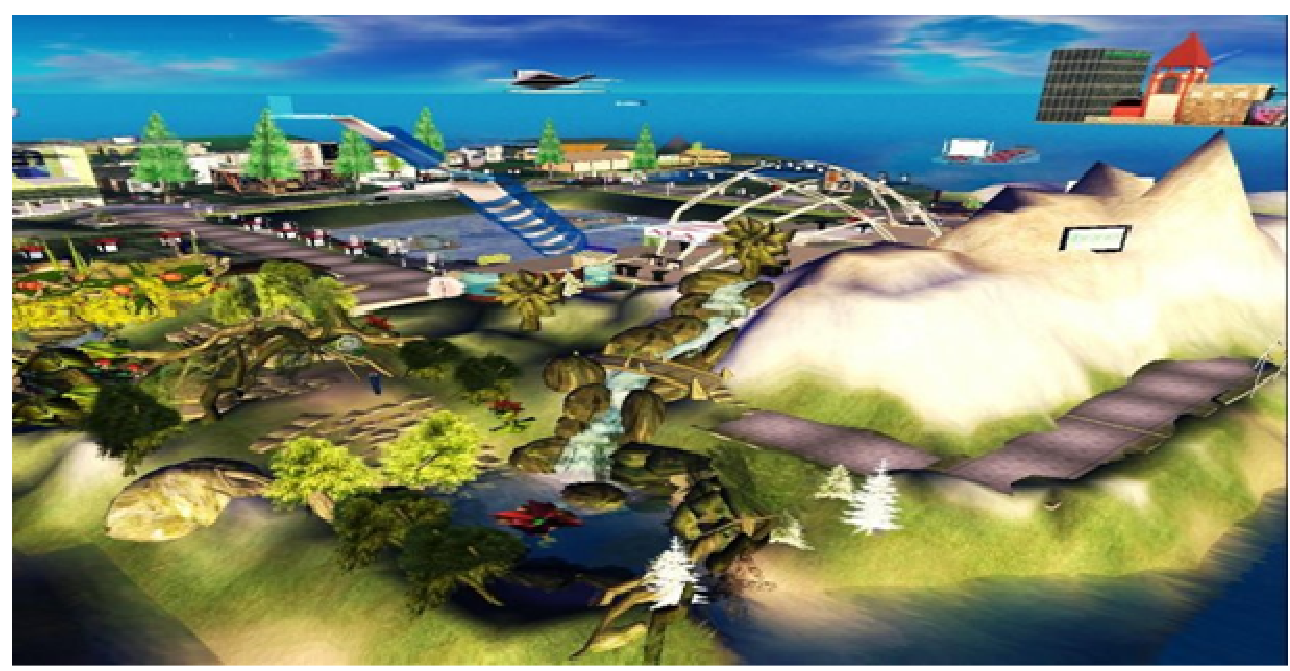

Fonte: ALA (2011) ${ }^{8}$.

A ilha ou território ocupado pela ALA no SL é denominada de ALA Island (Figura 1), o acesso à ALA Island é permitido a qualquer residente do SL. A propriedade da ALA Island é do grupo "ALA Artisans", que tem como fundador o residente Oberon Octagon, usuário do SL desde 11/09/2006. Oberon Octagon, Donavan Vicha (na vida física), participou

\footnotetext{
${ }^{7}$ Disponível em: <http://www.febab.org.br/>. Acesso em: 25 maio 2011.

${ }^{8}$ Disponível em: <http://www.flickr.com/groups/alasl/>. Acesso em: 14 mar. 2011.
} 
da implantação da ALA Island $\mathrm{e}$ atua como profissional no desenvolvimento de Recursos Web na ALA em Chicago (ALA, 2010).

As primeiras iniciativas da implantação da ALA no SL ocorreram em junho de 2007, durante a realização da Conferência Anual da ALA. Em reunião durante o evento, o comitê da ALA e mais 101 membros fundaram a American Library Association Virtual Communities e o Libraries Initiative Group e, na sequência, a ALA Island. No mesmo evento, foram iniciadas diversas participações em redes sociais, que corroboraram com a iniciativa de incluir a ALA e as bibliotecas do mundo na esfera virtual e da Web 2.0 (ALA, 2010).

No início de 2007, a Alliance Library System ${ }^{9}$ (ALS) cedeu uma ilha no SL para a ALA, que só foi aceita em novembro do mesmo ano. A partir da doação da ilha pela ALS e da ajuda da San Jose State University Graduate School of Library and Information Sciences ${ }^{10}$, Donavan Vicha e alguns alunos da universidade se reuniram e desenvolveram a ALA Island (ALA, 2010).

A infraestrutura da ALA Island é composta pela ALA Main Stage ou o Palco Principal da ALA Island, que possui uma total de $37.088 \mathrm{~m}^{2}$; foi arquitetada totalmente a céu aberto. Não existem paredes formando prédios ou salas, nem portas de acesso a qualquer espaço da ilha. Tal arquitetura remete ao conceito literal de Bibliotecas Virtuais ou de Bibliotecas Sem Paredes. Além disso, o palco principal da ALA faz referência ao Milennium Park de Chicago, que possui arcos que vão de um lado ao outro e formam um teto vazado e também a céu aberto. A semelhança com o Milennium Park pode ser considerada como uma homenagem à cidade natal da ALA, que é Chicago nos Estados Unidos da América (ALA, 2010).

Todos os espaços são decorados e remetem o avatar a sensações de semelhanças com espaços físicos da vida real conforme demonstra a Figura 2.

\footnotetext{
${ }^{9}$ Disponível em: <http://www.alliancelibrarysystem.com/>. Acesso em: 24 abr. 2011.

${ }^{10}$ Disponível em: <http://slisweb.sjsu.edu/>. Acesso em: 24 abr. 2011.
} 
Figura 2 - Espaços da ALA Island
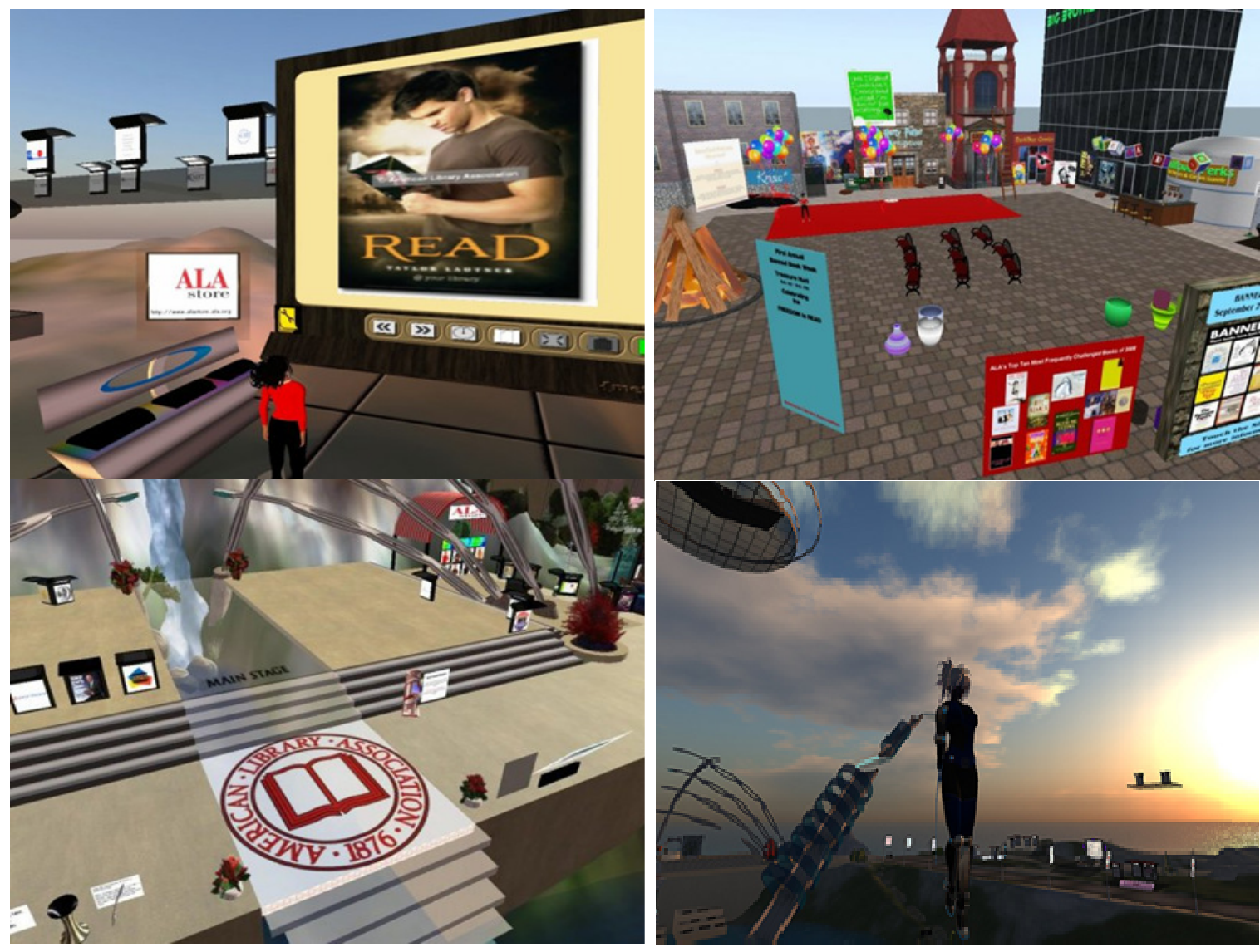

Fonte: ALA (2011)

\subsection{Os propósitos da ALA Island}

Em junho de 2010, a ALA completou três anos de atuação no SL, o que demonstrou que as iniciativas de inserção nas redes virtuais, sociais e da Web 2.0 certamente alcançaram resultados satisfatórios. A partir de análises efetuadas, tanto na ilha quanto no site da ALA, observou-se que a atuação da ALA em Ambientes Virtuais e, principalmente, de RV, como no SL, trouxe inovações para a Ciência da Informação e para a Biblioteconomia no mundo. Provavelmente, muitos bibliotecários e profissionais da informação desconheciam os ambientes de RV antes da atuação da ALA no SL.

Outro fato observado nas análises dos ambientes e recursos virtuais da ALA foi que a comunicação entre os bibliotecários e a ALA foi ampliada. Este fato pode ser comprovado pela existência das diversas Mesasredondas, pela participação de bibliotecas e bibliotecários nas Redes Sociais e Listas de discussão em que a ALA está inserida e, principalmente, pela permanência da ALA no SL há três anos. Todos esses fatores demonstram que os objetivos da ALA em buscar melhorias e

${ }^{11}$ Disponível em: <http://www.flickr.com/groups/alasl/>. Acesso em: 14 mar. 2011. 
avanços para a Ciência da Informação e para a Biblioteconomia e, principalmente, para os bibliotecários, estão sendo conquistados.

Em relação aos propósitos iniciais de implantação da ALA no SL, constatou-se que a iniciativa foi realmente da Alliance Library System (ALS). Os propósitos da ALA no SL para com os bibliotecários e para com o público em geral parecem ser os mesmos do espaço físico, que é promover os projetos de maior visibilidade da ALA e das bibliotecas e apoiar os bibliotecários em sua vida profissional.

Os resultados deste estudo demonstram que a repercussão da ALA no SL entre os bibliotecários é satisfatória, já que muitos bibliotecários enviam suas demonstrações de gratidão acompanhadas de elogios à ALA Island.

\subsection{Serviços e produtos informacionais da ALA Island}

A ALA disponibiliza aos bibliotecários diversos recursos informacionais, tanto de forma física quanto de forma virtual na ALA Island. A maioria dos espaços da ALA Island possui algum tipo de serviço ou produto informacional, como por exemplo: Salon Huron: os residentes podem ler ou ouvir algumas regras de comportamento para acesso à ALA Island.

ALA Office: apresenta os seguintes órgãos e organizações:

- ALA Washington Office ${ }^{12}$ : existente desde 1945, representa o Office of Government Relations (OGR) e o Office for Information Technology Policy (OITP);

- ALA Conference Services ${ }^{13}$ : informações sobre eventos, reuniões, simpósios, workshops, conferências, assim como seus respectivos registros, cartazes, calendários de programações, entre outras informações sobre eventos da ALA;

- ALA OFD - Office Divesity: acesso aos grupos que promovem a diversidade de redes e recursos para os bibliotecários;

- International Relations Office (IRO): tem como missão promover a ALA na comunidade global de bibliotecas;

- Chapter Relations Office (CRO) ${ }^{14}$ : apresenta discussões entre os 57 capítulos institucionais da ALA;

- ALA Public Programs Office: promove eventos culturais, como cursos e capacitação profissional; e

- ALA Recruitment Assembly ${ }^{15}$ : seção desenvolvida para promoção de Recursos Humanos e Recrutamento de pessoal.

Todos esses órgãos e organizações estão representados na ilha, por meio de quiosques informativos e pela indicação dos respectivos hiperlinks para acesso imediato pelo bibliotecário.

\footnotetext{
${ }^{12}$ Disponível em: <http://www.ala.org/ala/aboutala/offices/wo/index.cfm>. Acesso em:18 fev. 2011.

13 Disponível em: <http://www.ala.org/ala/conferencesevents/index.cfm>. Acesso em: 18 fev. 2011.

${ }^{14}$ Disponível em: <http://www.ala.org/ala/aboutala/offices/cro/index.cfm>. Acesso em: 18 fev. 2011

${ }^{15}$ Disponível em: <http://wikis.ala.org/recruit/index.php/Main_Page\#ALA_Recruitment_Assembly>. Acesso em: 19 fev. 2011.
} 
Galen Noltenius Sky Platform: estão disponíveis, nesse espaço, um e-book grátis e o acesso ao "I love libraries. org" ${ }^{16 ", ~ u m a ~ f o n t e ~ d e ~}$ informações para quem aprecia leitura e literatura.

ALA Park Central: nesse espaço existem pôsteres informativos sobre o jornal americano New York Times.

Virtual Commnunites e Library Membres Iniciative Groups: ambiente em que os eventos do grupo são visualizados em um banner gigante, e os websites da Virtual Presence ${ }^{17}$ e do ALAConnect ${ }^{18}$ podem ser manuseados em tela de tamanho igual ou maior que a altura do avatar. Os websites possuem sistema de rolagem instantâneo e dispensam o acesso aos hiperlinks das páginas na web.

Association of College \& Reasarch Libraries (ACRL): O local está repleto de indicação de hiperlinks, páginas acessíveis pelo próprio ambiente e em tamanho expandido. Nesse espaço, é possível, também, a visualização de fotos dos bibliotecários e avatares da ACRL, além da inscrição no RSS da organização.

ALAStore: espaço destinado para a comercialização de produtos da ALA, está representado também no Member Lounge. Na ALAStore o residente tem acesso a hiperlinks, como do site da ALAStore, do Book-list, publicações da ALA, entre outros. Além da comercialização de livros e revistas, a ALA possui, em sua lista de produtos, selos comemorativos, presentes como canecas, camisetas, marca-textos, entre outros. Ao visitar o estande da ALAStore, o avatar recebe descontos especiais, ao adquirir algum produto, e recebe camisetas gratuitas para o seu avatar.

Galen Noltenius Sky Platfor: espaço para relaxamento e leitura, com a disposição de puffs e poltronas para o avatar.

Member Lounge: espaço de atendimento de referência da ilha.

Banned Books Week Town Square: No local, o avatar encontra diversas referências a filmes e histórias famosas do cinema e da televisão e da literatura mundial que, por algum motivo, foram um dia banidos ou tiveram sua reprodução, comercialização e leitura proibidas por algum tempo.

American Association School Librarians (AASL): é mais um local para a realização de eventos, também denominado por ALA Main Campus.

A ALA disponibiliza diversos produtos e serviços informacionais na ALA Island. A maioria dos serviços e produtos da ALA também está disponibilizada fisicamente. No entanto, observa-se que a ALA procura atender os bibliotecários por mecanismos diversificados, como em Ambientes Virtuais e de Realidade Virtual como da ALA Island.

\footnotetext{
${ }^{16}$ Disponível em: <http://www.ilovelibraries.org/>. Acesso em: 19 fev. 2011.

${ }^{17}$ Disponível em: <http://www.virtual.ala.org/virtualpresence/>. Acesso em: 19 fev. 2011.

18 Disponível em: <http://connect.ala.org/dashboard?destination=node\%2F1>. Acesso em: 19 fev. 2011.
} 
Mais que serviços e produtos, a ALA demonstra aos bibliotecários novas formas de atuação em suas profissões. Os ambientes em 3D são espaços inovadores para a atuação de bibliotecários que buscam se atualizar juntamente com as tecnologias e tendências mercadológicas.

\subsection{Atendimento virtual}

$\mathrm{Na}$ ALA Island não existe atendimento virtual online aos bibliotecários. Os atendimentos são realizados por um robô da bibliotecária de referência da ilha, por notecards informativos e por indicação de hiperlinks atualizados constantemente.

O atendimento realizado pelo robô da bibliotecária acontece no espaço denominado por Member Lounge. É nesse local que o robô da bibliotecária de referência Val Miles presta atendimento virtual aos visitantes da ilha, por meio de um notecard com instruções básicas para os residentes, que pode ser acessado a qualquer momento.

No espaço da ALA Island não existe a representação das bibliotecas associadas, pois a atuação da ALA Island está focada nas relações entre os bibliotecários do mundo todo. Porém, a ALA está inserida num arquipélago envolto por outras ilhas relacionadas a bibliotecas e bibliotecários, como as ilhas de Cibrary City I e Cibrary City II $^{19}$, além da Info Island ${ }^{20}$, todas com objetivos de promover o acesso e o uso da informação e, também, as bibliotecas e unidades de informação pelo mundo. A participação da ALA nessas ilhas acontece esporadicamente, como, por exemplo, em eventos.

Ao que parece, a presença dos avatares dos bibliotecários da ALA Island acontece aleatoriamente, sem dias ou horários fixos. A exceção ocorre em dias de eventos realizados na ilha, o que, de acordo com análises realizadas nas Redes Sociais em que a ALA participa, atrai centenas de pessoas, por meio de seus avatares.

Para se obter um número aproximado de acesso e navegação da ALA Island, o usuário poderá se inscrever nos feeds RSS disponíveis em alguns espaços da ilha, como na AASL por exemplo. Por meio da assinatura do feeds, é possível acompanhar o fluxo de visitação de avatares em lugares específicos da ilha.

Os avatares dos bibliotecários visualizados em pôsteres na ALA Island e, também, nas Redes Sociais de que a ALA participa apresentam aparências diferentes e inexistentes da vida real, como, por exemplo, um bibliotecário representado por um avatar meio humano e meio leão (Figura 3), bibliotecários com cabelos prateados (Figura 3), com asas, rabos ou caldas, entre outros.

Figura 3 - Avatar do fundador da ALA Island e avatar da bibliotecária da ALA Marketing Merbership no SL

\footnotetext{
19 São ilhas destinadas à divulgação de bibliotecas, centros arquivísticos e unidades de informação de diversos locais do mundo.

20 Ilha destinada à discussão do uso e acesso à informação.
} 

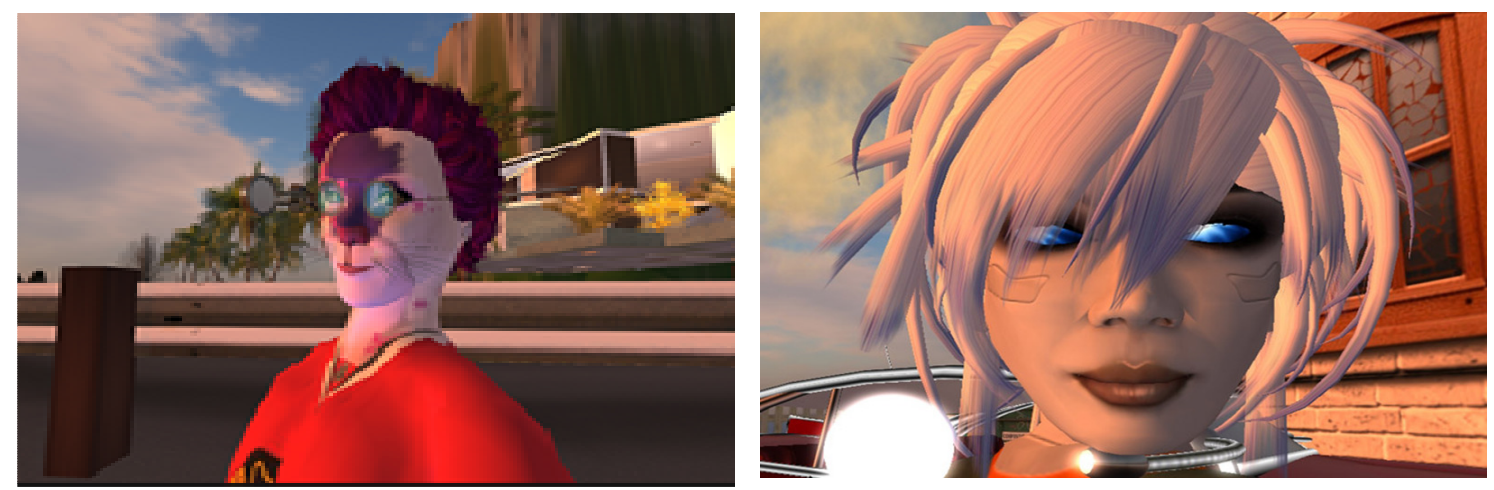

Fonte: Imagens cedidas pelos bibliotecários da ALA.

\subsection{Outros produtos da ALA na web}

A ALA participa de diversos recursos na web. Esses recursos são, em sua maioria, da Web 2.0, utilizados pela ALA para que ocorra o compartilhamento de informações e conhecimentos entre os profissionais da Biblioteconomia e da Ciência da Informação.

A ALA desenvolveu uma plataforma wiki para centralizar as informações sobre os recursos que disponibiliza na web. As wikis, que também são recursos da Web 2.0, são consideradas sistemas cujo conteúdo pode ser implantado, editado ou excluído sem que sejam necessárias intervenções de um mediador. Schons, Couto e Molossi (2007) relatam que a utilização de wikis em ambientes que concentram equipes de trabalho faz com que o conhecimento seja compartilhado e criem redes de informações de interesse em comum.

Na wiki principal da $\operatorname{ALA}^{21}$, estão listados todos os recursos web de que a ALA participa, além de outras quarenta e cinco wikis da ALA. Os recursos da web de que a ALA participa estão listados da seguinte maneira:

ALA Blogs 22: a ALA possui grande participação em Blogs, são quarenta e um no total, que discutem: a ALA e suas associações e projetos; serviços e tecnologia para os bibliotecários; publicações da ALA, entre outros assuntos sempre relacionadas à ALA, à Biblioteconomia e à Ciência da Informação. Todos os blogs da ALA possuem indicação de RSSfeeds para assinatura e acesso.

ALA Connect ${ }^{23}$ : é um recurso para a discussão de assuntos entre profissionais. O bibliotecário precisa estar cadastrado, seja como membro ou não-membro. O ALA Connect é um recurso desenvolvido pela ALA e está disponível em uma das extensões do site da ALA.

ALA Discussion Forums ${ }^{24}$ : fóruns direcionados para a discussão de assuntos das publicações periódicas da ALA, além de outros assuntos.

\footnotetext{
${ }^{21}$ Disponível em: <http://wikis.ala.org/readwriteconnect/index.php/Main_Page>. Acesso em: 23 mar. 2011.

22 Disponível em: <http://wikis.ala.org/readwriteconnect/index.php/ALA_blogs>. Acesso em: 23 mar. 2011.

${ }^{23}$ Disponível em: <http://connect.ala.org/>. Acesso em: 30 mar. 2011.

${ }^{24}$ Disponível em: <http://al.ala.org/forum/>. Acesso em: 12 fev. 2011.
} 
ALA Flickr Pictures ${ }^{25}$ : o Flickr ${ }^{26}$, também considerado como Rede Social (GONÇALVES, 2008), prevê o uso de fotografias e imagens para estabelecer relacionamentos entre pessoas. A ALA possui onze perfis no Flickr, sendo que os álbuns de fotografias estão relacionados com a ALA, seus membros, colaboradores, escritórios, eventos, associações, bibliotecas americanas, entre outros.

ALA Gadgets ${ }^{27}$ : neste item, estão disponibilizados três robôs de buscas em bibliotecas e serviços, possíveis a partir da utilização do Google Co-op, uma ferramenta que desenvolve buscas simultâneas em fontes selecionadas.

ALA Mailing Lists ${ }^{28}$ : apresenta aos usuários um recurso com mais de 160 Listas de Discussões, a maioria definidas como públicas (ALA WIKI, 2010). A ALA Mailing List está subdividida nas categorias de: ALA Governace, ALA Divisions, ALA Offices, Other ALA Units e a List by Subject.

ALA Member Initiative Groups ${ }^{29}$ : é uma página de extensão do site da ALA e está destinada ao Member Initiative Groups, Libraries Fostering Civic Engagement, Information Commons, Virtual Communities and Libraries e Games and Gaming in Libraries.

ALA Member Newsletter ${ }^{30}:$ um recurso de notícias direcionadas aos membros da ALA cadastrados. Porém, a página do recurso está offline.

ALA Podcasts ${ }^{31}$ : serviço de posts e podcasts da ACRL, do escritório da ALA em Washington, da Associação de Bibliotecas Públicas e da Associação de Serviços de Bibliotecas de Jovens e Adultos.

ALA on Social Networking Sites ${ }^{32}$ : apresenta a listagem dos recursos da ALA na Web 2.0: Facebook $^{33}$ (três perfis); Friendfeeds ${ }^{34}$ (três perfis); Linkedin $^{35}$ (dois perfis); LiveJournal ${ }^{36}$ (dois perfis); Myspace ${ }^{37}$ (quatro perfis); Ning ${ }^{38}$ (dois perfis); Twitter ${ }^{39}$ (dezoito perfis centrais); Del.icio.us ${ }^{40}$ (quatro perfis) e Youtube ${ }^{41}$ (quatro perfis).

\footnotetext{
${ }^{25}$ Disponível em: <http://wikis.ala.org/readwriteconnect/index.php/ALA_Flickr_pictures>. Acesso em: 23 mar. 2011.

${ }_{26}$ Disponível em: <http://www.flickr.com/>. Acesso em: 30 mar. 2011.

27 Disponível em: <http://wikis.ala.org/readwriteconnect/index.php/ALA_gadgets>. Acesso em: 23 mar. 2011.

${ }^{28}$ Disponível em: <http://lists.ala.org/sympa>. Acesso em: 23 mar. 2011.

${ }^{29}$ Disponível em: <http://www.ala.org/ala/mgrps/mcoms/migs/index.cfm>. Acesso em: 23 mar. 2011.

30 Disponível em: <http://www.ala.org/ala/alonline/aldirecta/aldirect.cfm>. Acesso em:23 mar. 2011.

${ }^{31}$ Disponível em: <http://wikis.ala.org/readwriteconnect/index.php/ALA_podcasts>. Acesso em: 23 mar. 2011.

32 Disponível em: <http://wikis.ala.org/readwriteconnect/index.php/ALA_on_social_networking_sites >. Acesso em: 30 mar. 2011.

${ }^{33}$ Disponível em: <http://www.facebook.com/>. Acesso em: 13 jun. 2011.

${ }^{34}$ Disponível em: <http://friendfeed.com/>. Acesso em: 13 jun. 2011.

${ }^{35}$ Disponível em: <http://www.linkedin.com>. Acesso em: 13 jun. 2011.

36 Disponível em: <http://www.livejournal.com/>. Acesso em: 13 jun. 2011.

${ }^{37}$ Disponível em: <http://www.myspace.com/>. Acesso em: 13 jun. 2011.

${ }^{38}$ Disponível em: <http://www.ning.com/>. Acesso em: 13 jun. 2011.

${ }^{39}$ Disponível em: <http://wikis.ala.org/readwriteconnect/index.php/ALA_Twitter_Feeds>. Acesso em: 13 jun. 2011.

${ }^{40}$ Disponível em: <http:// del.icio.us.com>. Acesso em: 13 jun. 2011.

${ }^{41}$ Disponível em: <Http://www.youtube.com>. Acesso em: 13 jun. 2011
} 
A ALA possui muitos recursos e ferramentas de acesso para bibliotecários e profissionais da informação. São projetos, associações, associados, colaboradores, eventos, história e muitas outras informações disponíveis aos bibliotecários do mundo todo.

São vários recursos com características diferentes, mas com objetivos em comum: informar, divulgar, promover, estabelecer relações mais próximas, encurtar distâncias geográficas, transpor barreiras financeiras, compartilhar a informação, o conhecimento, as soluções, as ideias, além de expandir conhecimentos sobre a Ciência da Informação e a Biblioteconomia.

De acordo com os dados obtidos, para que a ALA possa se manter no $\mathrm{SL}$, é necessário um pagamento mensal, de valor não informado durante a pesquisa, sendo que a ALA não possui patrocinadores ou parceiros que financiam ou colaboram com a manutenção da ilha.

\section{Considerações finais}

A ALA Island apresenta-se aos bibliotecários como uma extensão inovadora dos serviços e produtos da ALA. Os serviços na web são apresentados como formas diversificadas de comunicação e compartilhamento de informação entre os bibliotecários. No entanto, foi constatada a pouca adesão do Brasil e dos bibliotecários brasileiros na ALA, como um todo.

Atuar em espaços tão inovadores como os Ambientes Virtuais e de Realidade Virtual em 3D, como no Second Life, é, sem um dúvida, avanço muito importante para a Ciência da Informação e para a Biblioteconomia no mundo e, por isso, não pode ser ignorado ou não explorado. Oferecer serviços, produtos e informações em formato de 3D, num ambiente totalmente diferente do habitual, é estar sempre um passo à frente, diante da tecnologia e das necessidades de cada usuário.

Por conseguinte, constata-se que falta a compreensão e a adesão de toda a Ciência da Informação e da Biblioteconomia brasileira em espaços inovadores de atuação como o Second Life e a ALA Island. Pouca ou quase nenhuma participação de brasileiros foi encontrada nos diversos recursos em que a ALA está inserida, nem mesmo em blogs, wikis ou nos sites de relacionamento da ALA.

É necessário ressaltar que a ALA é precursora de diversos projetos sociais em que a biblioteca (tanto as públicas quanto as escolares e universitárias, entre outros tipos de unidades de informação) é a protagonista em ações de incentivo à leitura, à competência e de outros diversos projetos e campanhas.

A ALA disponibiliza, também, muitas opções de utilidade pública para os bibliotecários, como as relacionadas aos seus direitos e legislações em geral. Também oferece cursos e formação continuada a bibliotecários de qualquer parte do mundo, o que mostra que a ALA é uma organização completa. 
Portanto, é necessário que os bibliotecários e pesquisadores da Ciência da Informação e da Biblioteconomia brasileira estudem, compreendam e, principalmente, que explorem todos os serviços e produtos da ALA, assim como os ambientes virtuais e de Realidade Virtual em 3D do Second Life e da ALA Island.

\section{Referências}

ACCIOLY, M I. Um estudo exploratório sobre simulação e controle no Second Life. In: CONGRESSO BRASILEIRO DE CIÊNCIA E COMUNICAÇÃO, 30., 2007, Santos. Anais... Santos, 2007. p. 1-13. Disponível em:<http://www.intercom.org.br/papers/nacionais/2007/resumos/R07092.pdf. Acesso em: 7 jan. 2011.

AMERICAN LIBRARY ASSOCIATION (ALA). 2010. Disponível em: <http://www.ala.org/>. Acesso em: 28 jan. 2011.

ALA Flickr. 2011. Disponível em: $\overline{<\mathrm{http}: / / w w w . f l i c k r . c o m / g r o u p s / a l a s l />. ~ A c e s s o ~ e m: ~} 14$ mar. 2011.

ALA Wiki. 2010. Disponível em: http://wikis.ala.org/readwriteconnect/index.php/ALA_wikis>. Acesso em: 5 fev. 2011.

FERRAZ, P. Second Life para empreendedores: como iniciar sua segunda vida e ganhar dinheiro real no mundo virtual. São Paulo: Novatec, 2007.

GARCÍA, A. R. Second Life, qué hay detrás? 2007. 89f. Monografia de conclusão de curso (Graduação em Telecomunicação) - Escola Politècnica Superior de Castelldefels, Universitat Politécnica de Catalunya, Catalunya, 2007.

Disponível em:<http://upcommons.upc.edu/pfc/bitstream/2099.1/4576/1/memoria. pdf $>$. Acesso em: 8 mar. 2011.

GONÇALVES, A. P. Rede social na UM: um estudo de caso: análise e estratégias de utilizacão de portais situados na dinamizacão da rede social flickr. 2008. 111f. Dissertação (Mestrado em Engenharia de Redes e Serviços de Comunicação) - Escola de Engenharia da Universidade do Minho, Guimarães, Portugal, 2008. Disponível em: <http://repositorium.sdum.uminho.pt/bitstream/1822/9499/1/Disserta\% C3\%A7\%C3\%A30\%20de\%20Mestrado\%20-

\%20Alysson\%20Pires\%20Gon\%C3\%A7alves.pdf>. Acesso em: 5 fev. 2011.

KIRNER, T. G.; TOTI, A.; COSTA, P. L. V. A. A realidade virtual na biblioteconomia. In: SYMPOSIUM ON VIRTUAL REALITY, 8., 2006, BelémPA. Anais... Belém-PR, 2006. Disponível em: http://www.ckirner.com/download/capitulos/Fundamentos_e_Tecnologia_ de_Realidade_Virtual_e_Aumentada-v22-11-06.pdf >. Acesso em: 13 jan. 2011. 
MOURA, A.; CARVALHO, A. A. Aprender línguas estrangeiras no Second Life: reações dos alunos ao ambiente. In: SIMPÓSIO INTERNACIONAL DE INFORMÁTICA EDUCATIVA (SIIE), 9., 2007, Porto, Portugal. Anais... Porto, Portugal , 2007. p. 7-12. Disponível em: <http://repositorium.sdum.uminho.pt/bitstream/1822/7151/1/Moura\%26 Carvalho-SIIE-2007.pdf>. Acesso em: 17 mar. 2011.

O'REILLY, T. O que é web 2.0: padrões de design e modelos de negócios para a nova geração de softwares. 2006. Disponível em: <http://www.bibliotecavirtual.sp.gov.br/especial/docs/200905oqueeweb20.pdf>. Acesso em: 6 mar. 2011.

SCHONS, C. H.; COUTO, F. C.da S.; MALOSSI, S. O uso de wikis na gestão do conhecimento em organizações. Biblios: Revista de Bibliotecología y Ciencias de la Información, Peru, v. 8, n. 27, jan./mar. $2007 . \quad$ Disponível em: <http://dialnet.unirioja.es/servlet/articulo?codigo=2281812>. Acesso em: 11 jan. 2011.

SOARES, A. C. O Second Life na educação. 2009. 124f. Dissertação (Mestrado em Educação e Comunicação) - Universidade de Brasília, Brasília, 2009. Disponível em: <http://bdtd.bce.unb.br/tedesimplificado/tde_busca/arquivo.php?codArqu ivo=4876 > . Acesso em: 14 fev. 2011.

ZAGALO, N.; PEREIRA, L. Ambientes virtuais e Second Life. In: CARVALHO, A. A. (Org.). Manual de ferramentas da web 2.0 para professores. Lisboa (Portugal): Ministério da Educação, 2008. p.147-164. Disponível em: <http://repositorium.sdum.uminho.pt/handle/1822/8286>. Acesso em: 20 jan. 2011. 